\title{
Identifying the Factors Influencing the Development of eGovernment in Saudi Arabia: The Employment of Grounded Theory Techniques
}

\author{
O. Alfarraj, T. Alhussain, and A. Abugabah
}

\begin{abstract}
The implementation of eGovernment across countries is rapidly increasing. However, with this increase in the development of eGovernment projects especially in developing countries such as Saudi Arabia, there are still some difficulties facing the proper development of eGovernment. This paper aims to explore how eGovernment implementation and development can be understood in the context of Saudi Arabia based on the developers' perspectives. An attempt is made to identify the factors influencing the development of eGovernment and contribute to cause the delay of its initiatives at government organisations in Saudi Arabia. To achieve the aim, an unstructured interview within a qualitative approach was adopted in this study. Grounded theory techniques based on Strauss and Corbin approach (1990) were employed in this study in order to analyze the collected data.
\end{abstract}

Index Terms-eGovernment, implementation and development, Saudi Arabia.

\section{INTRODUCTION}

The focus of this study is the eGovernment concept in Saudi Arabia as one of these countries that still facing difficulties in implementation of its eGovernment. In actual fact, the Saudi Arabian government has already commenced implementation of its eGovernment concept named "Yesser" in 2005 [1]. Yesser is an umbrella for all eGovernment activities, procedures, legislations and other related issues and acts as the government's controller. The program has been launched and regulated in cooperation with three entities, which are the Ministry of Communication and IT, the Ministry of Finance and Communication, and the IT Commission [1]. Therefore, some eGovernment facilities are already in place. However, the duration of the eGovernment program, which has been set by the Saudi government, was not seem to be enough to achieve the expected outcomes according to what has been done so far and published in the literature. In particular, the Saudi government's clear statement regarding eGovernment, mentioned by several researchers such as [2], [3] as well as in several websites such as the Yesser eGovernment website (the official Saudi eGovernment website launched for the purpose of

Manuscript received January 5, 2013; revised March 12, 2013.

O. Alfarraj is with Griffith University (ICT School), Australia (e-mail: o.alfarraj@griffith.edu.au).

T. Alhussain is with Department of Computer Science at the University of King Faisal, Saudi Arabia (e-mail: talhussain@kfu.edu.sa).

A. Abugabah is with the American University in the Emirates, Dubai. (e-mail: ahed.abugabah@aue.ae).
eGovernment implementation), asserted that, "By the end of 2010, everyone in the kingdom will be able to enjoy from anywhere and at anytime - world class government services offered in a seamless user friendly and secure way by utilizing a variety of electronic means" Yesser Vision.

It is now 2012; Yesser eGovernment program has changed its vision from offering electronic services to be supporting the infrastructure projects especially at the government organisations due to the noticed weakness in the infrastructure at public sectors [1].

\section{AIM AND SIGNIFICANCE OF THIS STUDY}

The eGovernment phenomenon has become a wide area for research and study [4]. Yet, despite this emphasis on the concept of eGovernment in the literature, there is still a lack of research, especially on the factors that impede its applications and the reasons for this, specifically in Saudi Arabia [5]-[7]. Much of the published research regarding eGovernment in Saudi Arabia was considering the adoption side to the concept of eGovernment. However, most of the reviewed literature in relation to the eGovernment implementation at government organisations in Saudi Arabia was very few and their outcomes were as an expectation for the factors that might affect eGovernment during implementation process because the program of eGovernment has not accomplished during conducting previous research. Furthermore, most of the previous research about eGovernment implementation in Saudi Arabia used different research approaches which sometimes play role in reaching the results and clarifying the phenomenon being studied. In this study, the factors that influencing the implementation and development of eGovernment will be explored from the view of point the people who involved in the implementation of eGovernment and we call them here as developers.

\section{RESEARCH METHOdOLOGY}

This section provides information about the methodological stance that will adopt it in this study. This study adopts the unstructured interviews method within a qualitative approach. Moreover, the techniques of grounded theory based on the approach of Strauss and Corbin (1990) [8] were employed to analyze the collected data.

\section{A. Interview Method}

Qualitative interviewing is a type of interview method that 
is often associated with qualitative research and the one adopted in this study. It is not just a normal interview that stressed interviewing skills as it has generic characteristics, which include the flexibility in style of interview, focusing on people's actual experiences more than general beliefs, and stressing the relationship between the interviewer and interviewee that are considered as crucial to the method [9].

\section{B. Interview Sampling}

Twenty one in-depth interviews were conducted with different groups of participants involved in the implementation and development of eGovernment. These groups include IT managers, IT experts, members from eGovernment program, and IT academics engaged in the development of eGovernment. The current study adopts purposive or purposeful of sampling as it is considered to be the best for this study within a qualitative approach. Sampling in grounded theory is called 'theoretical' by most of researchers rather than 'purposeful' however, the two terms are interchangeable [10].

\section{Grounded Theory Techniques}

As mentioned, this study adopted the techniques of grounded theory derived from the approach of Strauss and Corbin (1990) [8]. As identified in the literature there are four main approaches/types of grounded theory used within IS research (as illustrated in the Table I) and analytic which is the use of grounded theory technique is one of them.

TABLE I: FOUR GROUNDED THEORY APPROACHES USED IN IS RESEARCH

\begin{tabular}{llllll}
\hline \hline Approach & Principles & Coding & $\begin{array}{l}\text { A priori } \\
\text { Theory }\end{array}$ & $\begin{array}{l}\text { Paradigm } \\
\text { model }\end{array}$ & $\begin{array}{l}\text { Typical } \\
\text { Refs }\end{array}$ \\
\hline Glaserian & Required & $\begin{array}{l}\text { Open, } \\
\text { Selective }\end{array}$ & No & $\begin{array}{l}\text { Viewed as } \\
\text { family of } \\
\text { codes }\end{array}$ & $\begin{array}{l}\text { Glaser } \\
\&\end{array}$ \\
Strauss \\
Straussian
\end{tabular}

Source: [13]

Using of grounded theory techniques here as an Analytical method, means using only the techniques and procedures of grounded theory to analyze the collected data and generate meaning for the area under study. The usage of grounded theory techniques for coding can be employed any or all of the three phases of coding (open, axial, and selective) and it does not required for multiple rounds of interviews as well as it does not require to stick with any particular formulation of grounded theory [11], [12]. Researchers using this approach usually come up with diagrams that explain the situations, events, people, and activities being researched through defining the relationships between categories and concepts that formed by codes and then create understandable meaning of this.

\section{The Use of Grounded Theory TeChNiQues to ANALYZE THE DATA}

This section will briefly explain the used of grounded theory techniques and procedures.

\section{A. Open Coding}

It is called initial coding which is the first phase/step in coding collected data. It is defined by [8] as "the process of breaking down, examining, comparing, conceptualizing, categorizing data". Data in this phase of coding is broken down into small pieces in order to manage it and conceptualize it through assigning a label to it that represent its meaning [8]. Table II shows an example for open code.

TABLE II: AN EXAMPLE FOR OPEN CODING

\begin{tabular}{lcc}
\hline Raw data (Example) & $\begin{array}{l}\text { Preliminary } \\
\text { code }\end{array}$ & Final code \\
\hline $\begin{array}{l}\text { Cooperation between government } \\
\text { sectors to develop the services is } \\
\text { needed, because in most cases } \\
\text { offering any service requires to } \\
\text { obtain and collect information } \\
\text { from more than a government }\end{array}$ & $\begin{array}{c}\text { Cooperation } \\
\text { between } \\
\text { gody. }\end{array}$ & $\begin{array}{c}\text { Cooperation to } \\
\text { develop/offer a } \\
\text { service }\end{array}$ \\
\hline \hline
\end{tabular}

In this study, open coding is considered as an initial step in the analysis process. A total of 320 codes were emerged and created based on 21 interviews. Two methods of coding were employed which are 1) In Vivo as referring to using the codes and terms that participants assign to their ideas and concepts during the interviews in order to preserve participants meaning regarding their views [14] and 2) Simultaneous Coding as referring to "the application of two or more different codes to a single qualitative datum, or the overlapped occurrence of two or more codes applied to sequential units of qualitative data" [15].

\section{B. Axial Coding}

It is the next procedure in grounded theory that comes immediately after the open coding step where the process of putting data back together takes place in this step in order to make connection and links (relationships) between categories [8]. It is also called theoretical coding where the process of referring sub-categories to their categories and making relationships among them is taking place in order to start creating meaning [11], [16]. This meaning should reflect what the empirical data is about regarding the factors influencing the development of eGovernment in Saudi Arabia.

In this analysis phase, codes were refined to find out core codes in order to compare these codes to others for the purpose of finding similarities and differences in terms of 
concepts that can be placed together within sub categories. The total major categories created in this phase of coding and after refining the categories are twelve major categories and given the names of 1) cooperation and collaboration, 2) organisations and needs at organisations, 3) IT professionals and IT skills, 4) eGovernment implementation and challenges, 5) awareness and training, 6) provision of electronic services, 7) education about the concept of eGovernment, 8) financial allocations and incentives for IT staff, 9) regulations \& procedures and plans, 10) e-readiness, 11) ICT infrastructure, 12) enablers. These main categories presented in Fig. 2.

\section{Selective Coding}

Selective coding or focused coding is closely similar to the axial coding but here it is on more abstract level [17]. The aim of this step of analysis is to find out the central category among created categories which will become the central of the research phenomenon and other categories will be surrounding the core category [8], [18], [19]. Determining the core phenomenon is based on showing the stress of the concept in the data through finding out how frequently the concept appears in the data. However, determining the frequencies based on the number of participants who mentioned particular concept rather than the number of times a concept appears in the data [20].

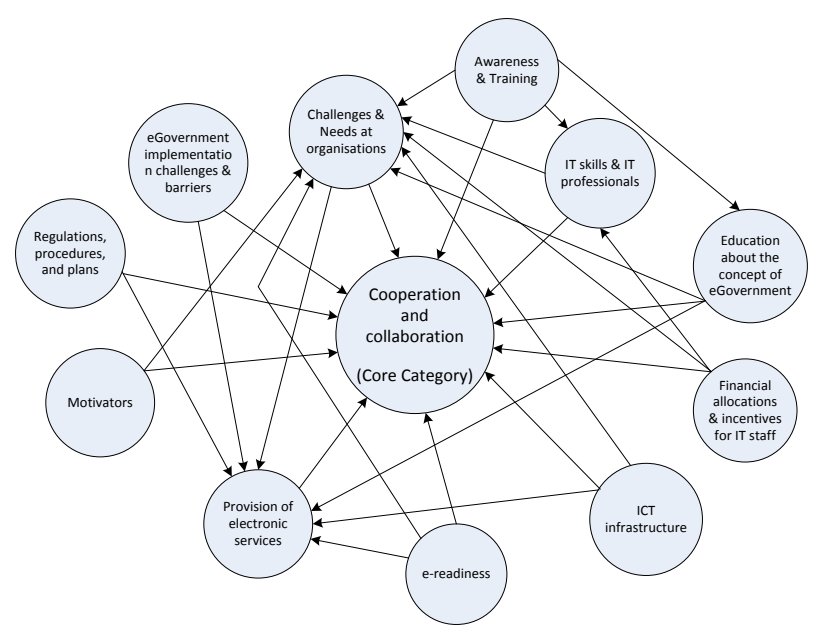

Fig. 1. Core category and relationships.

TABLE III: DETERMINING THE MOST FREQUENT CONCEPT IN THE DATA

\begin{tabular}{|c|c|c|}
\hline No. & Main concepts / Core codes & $\begin{array}{l}\text { Number of } \\
\text { participants }\end{array}$ \\
\hline 1 & Cooperation and collaboration & 16 out of 21 \\
\hline 2 & Challenges and Needs at organisations & 15 out of 21 \\
\hline 3 & IT skills and IT professionals & 14 out of 21 \\
\hline 4 & $\begin{array}{l}\text { eGovernment implementation challenges } \\
\text { and barriers }\end{array}$ & 14 out of 21 \\
\hline 5 & Awareness and Training & 14 out of 21 \\
\hline 6 & Provision of electronic services & 14 out of 21 \\
\hline 7 & $\begin{array}{l}\text { Education about the concept of } \\
\text { eGovernment }\end{array}$ & 13 out of 21 \\
\hline 8 & $\begin{array}{l}\text { Financial allocations and incentives for } \\
\text { IT staff }\end{array}$ & 10 out of 21 \\
\hline 9 & Regulations, procedures and plans & 10 out of 21 \\
\hline 10 & E-readiness & 9 out of 21 \\
\hline 11 & ICT infrastructure & 8 out of 21 \\
\hline 12 & Enablers & 7 out of 21 \\
\hline
\end{tabular}

The concept of 'cooperation and collaboration' was mentioned and stressed by sixteen participants and determined in this study to be the core concept (core category) as indicted in Table III and illustrated in Fig. 1. Maxwell [21] strongly advocates the integration of qualitative and quantitative approaches where appropriate especially using simple count of things.

\section{FACTORS INFLUENCING EGOVERNMENT IMPLEMENTATION AND CONTRIBUTING TO CAUSE THE DELAY OF ITS INITIATIVES}

The figure below summarized the results that been found in the empirical data to have an influence on the development of eGovernment and contributing to cause the delay of its initiatives at government organisations in Saudi Arabia.

\section{A. Cooperation and Collaboration Factors}

They refer to the factors that influencing the cooperation and collaboration of government sectors involved in the implementation process such as government sectors, Yesser eGovernment program as responsible for eGovernment implementation, and eServices developers. Cooperation factors are identified in this study to be the main influencing factors on the implementation of eGovernment and the important ones to contribute on causing the delay of its initiatives at government organisations in Saudi Arabia.

Cooperation and collaboration aspects include 1) cooperation of government sectors with Yesser program, 2) cooperation of government sectors with eServices developers to developer electronic services, 3) cooperation of government sectors with each other to transfer the required data for developing electronic services, 4) cooperation of the top managements with their departments within organisations to facilitate the implementation and development of eGovernment, 5) cooperation of financial departments with other internal departments within government sectors to facilitate funding the projects of IT, 6) and the cooperation of Yesser program and government sectors with researchers and research centers to conduct studies about eGovernment implementation and its issues.

These factors of cooperation are identified as the core group of factors or core phenomenon of this study that have a strong influence on the eGovernment implementation. As previously mentioned these factors of cooperation have an important influence on the implementation of eGovernment as for example Yesser team members lack for cooperation of government sectors with them in order to plan and design for eGovernment projects implementation. Another example for cooperation is the cooperation of IT departments within government organisations with their top managements. IT departments within organisations lack for the support and cooperation of their top managements to implement the project of IT. This lack of cooperation from the top management was associated by some participants to the lack of understanding and education to the concept of eGovernment (as discussed in organisational factors) within organisations by the employees and specifically the top managements.

\section{B. Organisational Factors}

This includes all factors that have an influence the implementation of eGovernment projects especially within 
organisations. As clarified in the figure, it is consists of six major categories that been created in the axial coding phase. These are as follows 1) education about the concept of eGovernment within government organisations, 2) The lack of financial allocations and incentives for IT staff that can motivate them to work effectively, 3 ) challenges and needs founded at government sectors to face the implementation process of eGovernment projects including understanding the concept of eGovernment and change management, 4) regulation, procedures and plans affecting the implementation and offering of electronic services at government organisations, 5) provision of electronic services at government sectors including the complexity in procedures while offering electronic services and the lack of linking government sectors electronically.

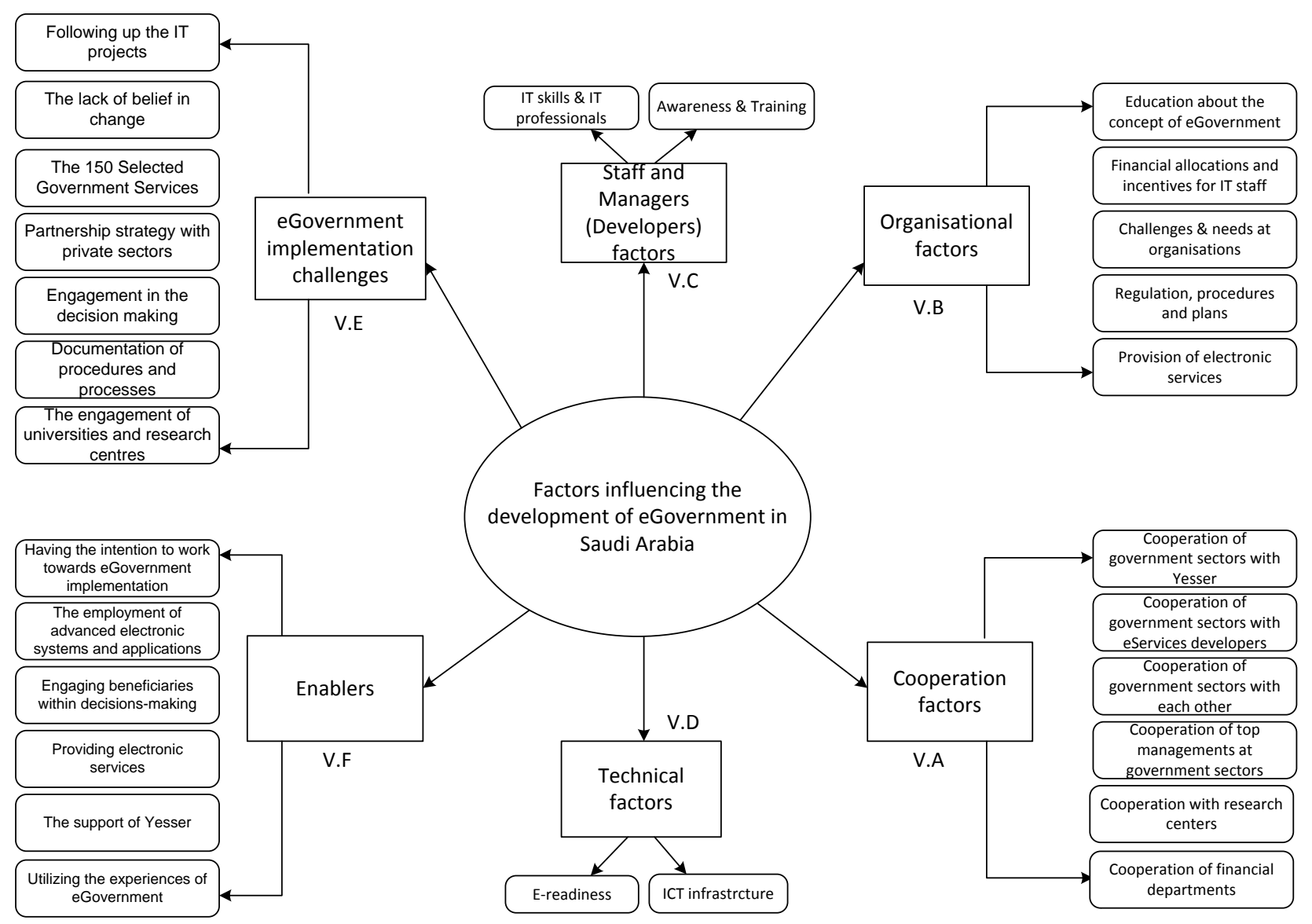

Fig. 2. Factors influencing the development of eGovernment in Saudi Arabia.

The impact of these factors has a great influence on the implementation of eGovernment project at government sectors as indicated by participants. For instance, the lack of understanding and education about the concept of eGovernment by employees and top managements at government sectors leads to increase the level of resistance against the implementation as some employees thought that it would affect on reducing the number of employees and limited the employment chances, losing the power for top managements. Another example is the lack of financial allocations and incentives for IT staff working at IT departments within organisations. Considerable number of participants indicated that current IT staff at government sectors does not have an enthusiasm to sincerely contribute on the development of eGovernment projects at their organisations because they lack for giving financial incentives and good salaries compared to the private sectors. Hence, this lack for financial allocations and incentives for IT staff has influenced the number of IT employees working at these IT departments within government sectors.

\section{A. Staff and Managers Factors}

Staff and managers factors are comprised of two main factors which are 1) IT skills and IT professionals, and 2) awareness and training for employees and top managements. These two factors were identified in the empirical data to have an influence on the implementation of eGovernment projects in Saudi Arabia. For example, the lack of IT staff and especially the qualified ones working at IT departments within government organisations is one of the factors included in this group. This lack in IT staff at government sectors affects the implementation of eGovernment at these sectors. Because the implementation of eGovernment and following up its initiatives would not be easy and possible without the help of IT staff. Therefore, IT staff at government sectors is the one who are going to assist Yesser eGovernment program to achieve its objectives and aim in implementation eGovernment at public organisations. Moreover, the results of this study indicate that IT staff working at government organisations lack for professional training that can enable them to play an active role in the implementation of eGovernment.

\section{B. Technical Factors}

Technical factors refer to the factors affecting the ICT 
capabilities in government organisations that can assist these organisations in delivering of electronic services as well as enhancing the communication between the sectors involved in the implementation of eGovernment projects. This group of factors include the technical issues that been found in the empirical data to have an influence on the implementation of eGovernment at some government sectors. This group contains two main factors which are 1) e-readiness and 2) ICT infrastructure. Mainly, they are two major categories that created in axial coding and developed in selective coding. One of the examples on the impact of these factors is that some participants indicated that there is a lack of cooperation between government sectors in terms of exchanging the required data for developing electronic services which mainly caused by the lack of e-readiness for some sectors. Such lack limits the ability of government sectors to electronically share data with other government sector. In most cases, offering electronic services by a government sector requires to obtain information or data from another sector to complete delivering the electronic service.

\section{Egovernment Implementation Challenges}

EGovernment implementation challenges are referred to the issues that been found in the data to have an influence on the projects of eGovernment at government sectors and especially concerned with Yesser eGovernment program. This group of factors includes several issues which are 1) The lack of following up the IT projects at government organisations; 2) the lack of belief in change by employees and top managements, 3 . the problem of specifying the 150 selected government services to start the implementation of eGovernment with, 3) The lack for establishing partnership strategy with private sectors to develop in implementing eGovernment at organisations, 4) engaging government organisations and other related entities in the decision making regarding developing electronic services, 5) the lack of documentation for procedures and processes during the development of eGovernment, 6) and lastly, the lack of engagement of universities and research centers with the development of eGovernment. One of the examples to the impact of the factors included in this group is that there are difficulties in following up the projects of eGovernment at government sectors. This is referred by some participants to several issues including the lack for institutional work with Yesser eGovernment program as well as the lack for IT staff at organisations. In order to maintain the progress of eGovernment projects at government sectors, Yesser has suggested to set up a steering committee in each government organisation that responsible for eGovernment implementation. As indicated by some participants from Yesser eGovernment program, this steering committee should include 1) the leader/head of that particular ministry as a director for this committee, 2) at least two IT persons as representing the IT department in that ministry, 3) and two employees from top management. Such strategy might help in enhancing the direct cooperation of government sectors with Yesser in order to follow up the progress of eGovernment projects implementation.

\section{Enablers factors}

This group of factors refer to the enabling factors, which enable achievement of eGovernment implementation and development at government organisations in Saudi Arabia. These issues include 1) Having the intention to work towards eGovernment implementation by government organisations, 2) The employment of advanced electronic systems and applications, 3) Engaging beneficiaries within decisions-making while offering electronic services, 4) Providing electronic services, 5) The continuous support of Yesser given to government organisations, and finally 6) Utilizing the experiences of eGovernment. One of the examples to show the impact of some factors mentioned in this section is that benefiting from the advanced experiences of others in eGovernment whether internal or external experiences. Some participants stressed on getting the benefit from the local experience in eGovernment development and activate it in other sectors where needed to, such as the experience of the Ministry of Higher Education as a good example in the country. Therefore, some participants indicated that Yesser has to play role in exchanging the successful experiences in relation to eGovernment development across the government organisations in the country.

\section{CONCLUSION}

This study explored the factors influencing the implementation and development of eGovernment and contributing to cause the delay of its initiatives at government organisations in Saudi Arabia.

The results indicate that cooperation and collaboration factors are the main and important factors that currently influencing the implementation of eGovernment in Saudi Arabia among other identified factors. Factors were presented in this paper in a general way and will be discussed in more details in future work as an extension to this paper.

\section{REFERENCES}

[1] Yesser Program Team 2010. Kingdom of Saudi Arabia e-Government Program (Yesser). The Ministry of Communication and Information Technology. Riyadh. KSA. [Online]. Available: http://www.yesser.gov.sa.

[2] A. Al-Soma, Saudi e-Government Yesser Plans and Achievements, Beirut, 2008.

[3] AL-Shehry, A. Rogerson, and S. Fairweather, "The Motivations for Change towards E-Government Adoption: Case Studies from Saudi Arabia," presented at eGovernment Workshop '06 (eGOV06), Brunel University, West London, UK, 2006.

[4] S. Alharbi, "Perceptions of Faculty and Students toward the Obstacles of Implementing E-Government in Educational Institutions in Saudi Arabia," Master thesis, West Virginia University, 2006.

[5] A. Al-Shehry, "Transformation Towards E-Government in the Kingdom of Saudi Arabia: Technological and Organisational Perspectives," Doctoral thesis, De Montfort University, Leicester, UK, 2008.

[6] T. Altameem, "The critical factors of eGovernment adoption: An Emprical study in the Saudi Arabia public sectors," Doctor of Philosophy thesis, Brunel University, 2007.

[7] M. O. Al-Fakhri, R. A. Cropf, P. Kelly, and G. Higgs, "E-Governmen in Saudi Arabia: Between Promise and Reality," International Journal of Electronic Government Research (IJEGR), vol. 4, no. 2, pp. 59-85. 2008

[8] A. L. Strauss and J. Corbin, Basics of qualitative research: Grounded theory procedures and techniques, California: Sage Newbury Park, 1990, pp. 61

[9] N. King and C. Horrocks, Interviews in Qualitative Research, Sage Publications Ltd., 2009. 
[10] J. R. Cutcliffe, "Methodological issues in grounded theory," Journal of Advanced Nursing, vol. 31, no. 6, pp. 1476-84, 2000.

[11] R. Matavire and I. Brown, "Investigating the use of Grounded Theory in information systems research," in Proc. Annual Conference of the South African Institute of Computer Scientists and Information Technologists, South Africa: Wilderness, 2008, pp. 139-47.

[12] D. Furniss, A. Blandford, and P. Curzon, "Confessions from a grounded theory PhD: experiences and lessons learnt," in Proc. the 2011 annual conference on Human factors in computing systems, Vancouver, BC, Canada, 2011, pp. 113-22.

[13] R. Matavire and I. Brown, "Investigating the use of Grounded Theory in information systems research," in Proc. Annual Conference of the South African Institute of Computer Scientists and Information Technologists, South Africa: Wilderness, 2008, pp. 139-47.

[14] K. Charmaz, Constructing grounded theory: A practical guide through qualitative analysis, Sage Publications Ltd., 2006.

[15] J. Saldaña, The coding manual for qualitative researchers, Sage Publications Ltd., 2009, pp. 55.

[16] I. Dey, Grounding grounded theory, CA: Academic Press San Diego, 1999.

[17] J. C. Niekerk and J. Roode, "Glaserian and Straussian grounded theory: similar or completely different?" in Proc. the 2009 Annual Conference of the South African Institute of Computer Scientists and Information Technologists, Vanderbijlpark, South Africa, 2009, pp. 96-103.

[18] J. W. Creswell, Educational Research: Planning, Conducting, and Evaluating Quantitative and Qualitative Research, 3rd ed., Pearson Education International, 2008.

[19] J. Creswell, Qualitative Inquiry and Research Design: Choosing Among Five Approaches, third ed., Sage Publications, Inc., 2012.

[20] E. Namey, G. Guest, L. Thairy, and L Johnson, Data reduction techniques for large qualitative data sets, eds G. Guest and K. M. MacQueen, UK: Altamira Press, 2008.

[21] J. A. Maxwell, "Using numbers in qualitative research," Qualitative Inquiry, vol. 16, no. 6, pp. 475-82, 2010.

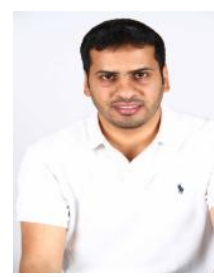

Osama Alfarraj is a $\mathrm{PhD}$ student in the school of Information and communication technology, Griffith University, Brisbane, Australia. Osama was born in 1980 in Riyadh; the capital city of Saudi Arabia Osama's doctoral dissertation investigates the factors influencing the development of eGovernment in Saudi Arabia and it is a qualitative investigation of the developers' perspectives. He has a Master degree in Information and Communication Technology from Griffith University in 2008. His research interests include electronic commerce, M-government, and the eHealth systems.

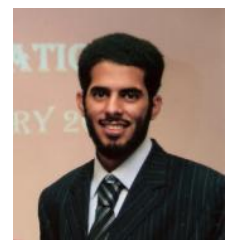

Thamer Alhussain is an assistant professor in the Department of Computer Science, College of Computer Sciences and Information Technology, King Faisal University, Saudi Arabia. Thamer was born in Riyadh in Saudi Arabia. Thamer's doctoral dissertation investigated the factors influencing the adoption of biometrics in $\mathrm{m}$-government applications; and his $\mathrm{PhD}$ degree from the School of Information and Communication Technology at Griffith University in Australia. He has a Master degree in Information and Communication Technology from Griffith University as well. Thamer also obtained a Graduate Certificate in Information Systems from Griffith University. His research interests include mobile services, e-government, and adoption of biometric technology.

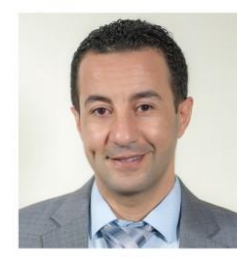

Ahed Abugabah is an assistant professor of Information Systems (IS) at the American University in the Emirates, Dubai. He was born in Jordan. He holds a BA and a master degree in business administration, Graduate certificate and a $\mathrm{PhD}$ in information systems. Before joining the academia, he has held a senior position in the airlines industry. His research interests include information systems and user performance, information systems models, user evaluations, and information systems in the health sector. 